\title{
Addressing Health Insurance Deductions through an Interventional Study: the Case of a Large Central Hospital
}

\author{
E Kharazmi, A Salehi, N Hashemi, S Ghaderi and N Hatam
}

\begin{abstract}
Objective: A large proportion of hospitals' private income is provided by insurance organisations. Hospitals in Iran face various problems in terms of insurance deductions from insurance organisations resulting from inefficient performance by both the hospitals and the insurers. These problems necessitate more specific cost control in this area. This research assesses the causes of insurance deductions by using the Failure Mode Effects Analysis (FMEA) technique, and addresses the issues resulting in deductions by providing some interventions through the Pareto technique.
\end{abstract}

Design: The 10-step pattern of FMEA was implemented for assessing the main causes of insurance deduction in this study.

Setting: Data was collected from deduced amounts by three main/largest contracting party insurance organisations (e.g. the Social Security Insurance Organisation, Medical Services Insurance Organisation and Armed Forces Medical Services Insurance Organisation of Namazi Hospital, a large healthcare provider in the South of Iran, in 2014.
Findings: Sixty-five potential failure causes were identified, of which 26 were related to the anaesthesia unit, 23 were related to the surgery room unit and 16 were related to the hospitalisation unit. Deductions in the anaesthesia and hospitalisation units and the surgery room were reduced after intervention programs by $14.42 \%, 57.76 \%$, and $51.52 \%$, respectively.

Conclusions: Using the FMEA technique in a large healthcare provider in Iran resulted in identifying the main causes of insurance deductions and provided intervention programs in order to increase the efficiency and productivity of healthcare services.

Abbreviations: FMEA - Failure Mode Effects Analysis; RPN - Risk Priority Number.

Key words: health insurance; hospital; FMEA analysis; pareto analysis; Iran.

\section{Erfan Kharazmi}

School of Health Management and Information Sciences Shiraz University of Medical Sciences

Shiraz, Iran.

\section{Asiyeh Salehi}

Menzies Health Institute Queensland

Griffith University

Queensland, Australia.

\section{Neda Hashemi}

Menzies Health Institute, School of Medicine

Griffith University

Queensland, Australia.

\section{Shekufe Ghaderi}

School of Health Management and Information Sciences Shiraz University of Medical Sciences

Shiraz, Iran.

\section{Nahid Hatam}

Full professor, School of Health Management and Information Sciences

Shiraz University of Medical Sciences

Shiraz, Iran.

Correspondence

nedahashemi86@yahoo.com 


\section{Introduction}

The growth of expenditure in healthcare systems is affecting the delivery of high quality services. The largest portion of healthcare costs $(60-80 \%)$ is allocated to hospitals as the main component of the healthcare system. [1,2] Investigations show that the allocation of healthcare costs to hospitals in 12 Asian countries varies between $33-70 \%$. [2] In Iran healthcare expenditure has also been increasing rapidly during the recent years and has placed critical resource pressures on the healthcare system. [3]

This presents hospitals with challenges in providing the financial resources to deliver high quality healthcare services. [4] The way that hospitals obtain monetary resources depends on their ownership type. In private hospitals the resources are principally supplied from the hospital's private income, while public hospitals fund their basic financial resources from the general government budget. These hospitals use private income as supplementary financial resources. [5] In Iran, after implementing the hospital autonomy plan in 1995, the state budgets were discontinued and from 1997, financial credits were enacted to provide the stipends (salary) only. As a consequence, the state budgets lost their role as the main monetary resource for public hospitals, and the hospitals themselves were responsible for their financial resources; thus selling services and private income became their major financial supply. [6]

A large proportion of hospitals private income is provided by insurance organisations. [7] According to an investigation, general and private hospitals are able to gain $62.05 \%$ of their funds from private income, of which $56.10 \%$ comes from insured patients and $5.95 \%$ comes from noninsured ones. [8] The number of insured people is growing, and thus, the important role of insuring organisations in supplying the income of hospitals is increasing. [9] However, as evidence shows, hospitals face various problems with their contracting party insurances, and in some cases, the insurance organisations place hospitals under financial stress. According to the literature, one of the most significant pressures on hospitals is insurance deductions. In other words, in the majority of cases insurance companies deduct part of the total requested amounts from hospitals after monthly investigating their financial documents. These deductions cause dissatisfaction among contracting hospitals, intensified by delays in the payment of their claims. According to existing statistics, $80 \%$ of the bills sent by hospitals are reduced before investigating and removing errors and hospital requested claims are paid sometimes with 9-12 months delay by insurance organisations. [8]

According to the literature, deductions by insurers cause problems both for hospitals and insurance organisations. For hospitals, the reduced amounts are part of the income that is actually not received, and for insurers, the bills and documents with deductions require more investigation, demanding more costs and taking more time. Therefore, describing the causes of insurance deductions can be beneficial to a large extent in this context. In fact, through identifying the causes, the patients' bills can be prepared quickly and accurately by hospitals, can be sent in a timely way to the insurance organisations and can be investigated promptly by them.

Furthermore, investigating the causes of insurance deductions provides valuable information to hospital managers about existing weaknesses, thus enabling them to reduce deductions and increase hospital income. [10] The present study was devoted to investigating the main causes of insurance deductions by using the Failure Mode Effects Analysis (FMEA) technique and then resolving them using the Pareto technique. [7] The case studied in this paper is Namazi Hospital, the largest public hospital in the south of Iran, located in Shiraz city.

\section{Methods}

The current study involved the three main/largest contracting party insurance organisations of Namazi Hospital including the Social Security Insurance Organisation, the Medical Services Insurance Organisation, and the Armed Forces Medical Services Insurance Organisation.

The existing data of reduced amounts by these three insurance organisations in 2014 (21st March till 21st June) were collected and organised based on the types of the services they provided. As the anaesthesia and hospitalisation units and the surgery rooms had the highest amount deducted by each of the three insurers, only deductions related to these three units were investigated.

The FMEA technique was used to assess the main causes of insurance deduction. FMEA is a systematic, proactive technique for evaluating the hazards of a process malfunction, to make decisions about where to execute progress actions, and to assess the effect and outcome of those actions. [11] Accordingly, the 10-step recognition pattern of FMEA was implemented through the following steps. [12-14] 


\section{Reviewing the key process steps}

The flowcharts of activities in anaesthesia unit, surgery room and hospitalisation units in the Department of Health Economics (as the responsible unit for controlling, investigating and sending the documents to insurance companies) were plotted. The flowcharts indicated that some of the processes applied in recording the activities led to missed or incorrect records. This caused an increase in insurance deductions.

\section{Step 1: Listing the potential failure mode}

Based on the flowcharts of the previous step, all failure causes were identified with the cooperation of experts in the Health Economy Unit through brainstorming. A complete list of wrong process steps and inputs was prepared.

Step 2: Specifying the effects of the potential failure mode Through listing the failure causes on the data collection form, the health economics experts identified the effects of the potential failures, on the anaesthesia unit, surgery room and hospitalisation units.

\section{Step 3: Specifying the severity degree of each effect} With the cooperation of health economics experts, the severity degree of each potential failure mode effect was ranked from one (being not severe at all) to ten (being extremely severe).

\section{Step 4: Identifying the occurrence rate of the failure mode/ effect}

The occurrence rate of each failure mode was specified based on the data obtained from exploring the causes of deductions in the patients' records. The occurrence was ranked from one (highly unlikely to ever occur) to ten (likely to happen all the time).

Step 5: Specifying the probability of detection to each failure mode/effect

The probability of detection indicates how a failure/effect is likely to occur. Based on the controls in place, the health economics experts ranked the detection probability from one (the failure/effect is fully detectable) to ten (the failure/ effect is quite undetectable).

Step 6: Allocating a Risk Priority Number (RPN) to each failure mode/effect

The RPN is calculated by multiplying the Severity (S), Occurrence $(\mathrm{O})$, and Probability of detection $(\mathrm{P})$ numbers: $\mathrm{RPN}=\mathrm{S} \times \mathrm{O} \times \mathrm{P}$

This is a key number that determines which potential failure mode has the most priority and should be focused on first.

Step 7: Sorting the failure mode/effects by RPN number

The failure/effects were sorted in descending order by the
RPN scores. The priority of the failure modes was specified for the anaesthesia unit, surgery room and hospitalisation unit based on the RPN. Then the Pareto technique and the 20:80 rule were applied to determine the failure/effects that required intervention. The 6-stage Pareto pattern is as follows:

Stage 1: Identifying the problems to be solved

The potential failure causes with the highest RPN score within the spring of 2014 (21st March till 21st June) were determined as the target problems to be resolved.

Stages 2 and 3: Recording the observed problem cases on a data record sheet to calculate their frequencies/scores

In the present study, the RPNs of the failure causes were considered as the frequencies or scores of the observed problems.

Stages 4 and 5: Preparing a frequency distribution table

During this stage, the problems were grouped together by cause. The frequency distribution table was prepared for each of the units studied. The table included the failure causes with the highest RPNs, the frequency column and the cumulative frequency column.

Stage 6: Drawing the Pareto chart

Pareto charts of failure causes were drawn for the anaesthesia unit, the surgery room and the hospitalisation units.

Step 8: Taking appropriate actions to remove or reduce the causes with high priority

In this step, the failure causes, which were in the risky region according to the Pareto chart, were selected for intervention during the summer of 2014 (21st June till 21st September). The intervention types were selected by consulting the health economics experts inside and outside of the hospital. The interventions included training and consulting staff of the relevant units about correct filling of the sheets related to the activities done for each patient, and negotiation with insurance organisations to convince them to undertake some treatment costs.

Step 9: Recalculating the RPN after intervention and/or remove the effects of potential failure causes

The risk priority numbers were recalculated for cases with the highest RPN values to specify the efficiency of the FMEA technique. The Pareto charts were also redrawn for the anaesthesia and hospitalisation units and the surgery room.

\section{Results}

The FMEA technique was conducted in three main units of Namzi hospital including the anaesthesia and hospitalisation units and the surgery room, as the units with the highest deductions in patients' records. Sixty-five potential failure 
causes were identified, of which 26 were related to the anaesthesia unit, 23 were related to the surgery room unit and 16 were related to the hospitalisation unit.

The RPN scores calculated for the failure causes revealed that the highest RPN value in the hospitalisation unit was related to 'not sealing/signing the procedure sheet by the physician' (RPN = 320) and the lowest RPN value was related to 'incorrect date recording on the visit sheet' (RPN $=40$ ). In the surgery room, 'additional surgery room code,' 'wrong surgery room code,' 'excess percentage for the surgery room', 'additional surgery commission code' and 'excess percentage of surgery commission' had the highest RPN values (each with RPN of 350) and 'not considering the surgeon assistant' had the lowest score (RPN = 24). The highest RPN value in the anaesthesia unit belonged to 'code 51 of anaesthesia' (RPN $=1000)$ and the lowest belonged to 'adjusting the cardiac anaesthesia shorter than four hours' (RPN $=20)$.

Pareto charts obtained before and after intervention in each of the hospitalisation units and the surgery room indicated that:

- Out of 16 failure causes related to deductions of the hospitalisation unit, ten cases had the largest influence on deductions (Figure 1). In other words, $80 \%$ of deductions related to the hospitalisation unit were revealed to originate from ten of the failure causes. Five out of the ten causes were intervened, which are presented in Table 1 at the end of the article with their RPN scores before and after the intervention.

- Out of 23 failure causes related to deductions of the surgery room, 12 were risky (Figure 2). In the present study, six out of the 12 causes were intervened, which are presented in Table 2 with their RPN scores before and after the intervention.

- Out of 26 failure causes related to deductions of the anaesthesia unit, 11 causes were risky (Figure 3). In this study, four of these causes were intervened. Table 3 presents descriptions and RPN values of these causes before and after the intervention.

As Tables 1-3 appearing at the end of the article indicate, the RPN values after intervention has decreased in comparison with the values before intervention. This means that the failure causes and consequently the deductions have decreased in all the three units. The anaesthesia unit had the largest ratio of deductions by all three insurance companies. Deduction amount in this unit was (US) $\$ 14,590$ in the spring of 2014, which has decreased to (US) $\$ 12,487$ in the summer of the same year (14.42\%). The amount of deductions by the three insurance companies in the surgery room has decreased from (US) $\$ 2,185$ in the spring of 2014 to (US)\$923 in the summer (57.76\%). In the hospitalisation unit, (US) $\$ 53,182$ was deducted during the spring of 2014, which has decreased to (US)\$25,786 in the summer (51.52\%). These reductions consequently resulted in the increase of the hospital revenue.

\section{Discussion}

Insurance deduction is a significant issue in healthcare systems that could result in major financial challenges for hospitals. Considering this problem, the present study investigated the insurance deduction amounts and their causes in Namazi Hospital as the major healthcare provider in the south of Iran. The FMEA technique was applied for this purpose and, an intervention was taken through the Pareto technique. As a result, the findings demonstrated decreases of the RPN values related to all intervened failure causes.

Recently FMEA has been used in many healthcare organisations and hospitals in order to improve their processes. In agreement with the current study, other research indicates the usefulness of this instrument in various healthcare services. For example Capunzo et al (2004) experimented with the application of FMEA technique in a clinical laboratory. [11] In addition, intervention programs in the Child Cancer unit by Van Tilburg et al (2005) and Robinson et al (2006) resulted in removing ten high risk failures in the first study, and decreasing the potential mistakes by $9 \%$ in prescriptions while increasing the use of standard prepared prescription packages by $23 \%$ in the second study. [15-16]

Adachi and Lodolce (2002) also applied the FMEA method to increase confidence in administering venous medications. According to this study, incorrect dosage included $17 \%$ of iatrogenic mistakes, with the incorrect adjusting of venous injection pumps being the most prevalent failure cause (41\%). One year after intervention, the number of iatrogenic mistakes related to drug administration dropped from 59\% in 2002 to $46 \%$ in 2003 and the wrong adjustment of injection pumps decreased from $41 \%$ in 2002 to $22 \%$ in 2003. [17] In a similar study by Apkon et al (2004) failure causes with RPN values higher than 225 decreased to fewer than 100 at the end of intervention. [18] Wetterneck et al (2006) also used the FMEA technique to evaluate the intelligent injection pumps and presented reforming suggestions for 13 out of 18 failure causes. [19] These studies indicate the usefulness of FMEA in identifying malfunction of different healthcare services and providing possible intervention programs. 
In the present study, the most prevalent causes of insurance deductions are related to the physician not sealing and not signing the procedure sheet, not recording the date of releasing the result in the consult sheet, incomplete filling in the visit sheets, not recording the date on the visit sheet, altered procedure sheet in hospitalisation unit, wrong coding in surgeries and incorrect filling in the anaesthesia sheet. Accordingly, in a study by Fatehi Peykani in 1999 in Iran, the main causes of deductions of inpatients' bills were shown to be the wrong coding of surgeries, not executing the general regulations, mistakes in calculating the tariffs, lack of documents in patients' records, excess price and differing global general tariff. [20] An investigation by the Quality Improvement Committee of Tehran University of Medical Sciences in 2001 also demonstrated that not writing prescriptions and not describing the operation by physicians, untimely sending of the para-clinical reports, lack of documents sent by hospital units, lack of practical commitment by the organisation and experts to educational issues (for educational health centres), incorrect bill preparation (not sealing by the technician and not mentioning the price), staff inpatient discharge and accounting units not informed of the latest circulars, lack of human resources, lack of tariffs in some new specialist services, lack of unanimity between the two parties, problems in confirming the operation and/or the insurance handbook before hospitalisation are known as the prevalent causes of deductions. [21]

\section{Conclusions}

In general, results of the present study indicate that not-socomplicated actions to remove the insurance deductions in different hospital units will result in remarkable benefits, such as increasing the revenue of hospitals as well as saving the time and work expenses, which consequently enhance the efficiency and productivity of healthcare services. This is particularly essential for Namazi Hospital as the most important healthcare provider in the south of the country, especially considering the growing population and the increasing number of children and the elderly.

\section{Competing Interests}

The authors declare they have no completing interests.

\section{References}

1. Nouroozi T, Salehi A. Prime costs of clinical laboratory services in Tehran Valiasr Hospital in 2009/Coût primaire des services de laboratoires cliniques à l'hôpital Valiasr de Téhéran en 2009. East Mediterr Health J. 2013;19(3):S159.

2. Hatam N, Keshtkar V, Salehi A, Rafei H. The financial cost of preventive and curative programs for breast cancer: a case study of women in Shiraz-Iran. Int J Health Policy Manag. 2014; 2(4):187-91.

3. Davari M, Haycox A, Walley T. Healthcare financing in iran; is privatization a good solution? Iran J Public Health. 2012; 41(7):14-23.

4. Kalhor R, Salehi A, Keshavarz A, Bastani P, Heidari Orojloo P. Assessing hospital performance in Iran using the Pabon Lasso Model. Asia Pac J Health Manag. 2014;9(2):77-82.

5. De Souza Mario C, Francis C. Hospital Administration. New Delhi: Jaypee Brothers; 2004.

6. Jafari M, Rashidian A, Abolhasani F, Mohammad K, Yazdani S, Parkerton $\mathrm{P}$, et al. Space or no space for managing public hospitals; a qualitative study of hospital autonomy in Iran. Int J Health Plan Manage. 2011;26(3):1-17.

7. Marnani AB, Teymourzadeh E, Bahadori M, Ravangard R, Pour JS. Challenges of a large health insurance organisation in Iran: a qualitative study. Int J Collab Res Internal Med Public Health. 2012;4(6):1050-62.

8. Davari M, Haycox A, Walley $T$. The Iranian health insurance system past experiences, present challenges and future strategies. Iran J Public Health. 2012;41(9):1-9.

9. Ibrahimipour H, Maleki M-R, Brown R, Gohari M, Karimi I, Dehnavieh R. A qualitative study of the difficulties in reaching sustainable universal health insurance coverage in Iran. Health Policy Plan. 2011;26(6):485-95.

10. Hasani SA, Abolhalaj M, Behmaneshnia M, Bastani P, Ramezanian M, Najafi B, et al. Specific Revenue of Iranian Medical Science Universities within 2001-2010. World Applied Sciences Journal. 2013;22(4):479-84.

11. Capunzo M, Cavallo P, Boccia G, Brunetti L, Pizzuti S. A FMEA clinical laboratory case study: how to make problems and improvements measurable. Clin Lead Manag Rev. 2004; 18(1):37-41.

12. Esmail R, Cummings C, Dersch D, Duchscherer G, Glowa J, Liggett $G$, et al. Using Healthcare Failure Mode and Effect Analysis tool to review the process of ordering and administrating potassium chloride and potassium phosphate. Healthc Q. 2005;8(spec no): 73-80.

13. Day S, Dalto J, Fox J, Turpin M. Failure mode and effects analysis as a performance improvement tool in trauma. J Trauma Nurs. 2006;13(3):111-7.

14. McNally KM, Page MA, Sunderland VB. Failure-mode and effects analysis in improving a drug distribution system. Am J Health-Syst Pharm. 1997;54(2):171-7.

15. Van Tilburg CM, Leistikow IP, Rademaker CMA, Bierings MB, van Dijk ATH. Healthcare Failure Mode and Effect Analysis: a useful proactive risk analysis in a pediatric oncology ward. Qual Saf Health Care. 2006;15(1):58-64.

16. Robinson DL, Heigham M, Clark J. Using Failure Mode and Effects Analysis for safe administration of chemotherapy to hospitalized children with cancer. Jt Comm J Qual Pat Saf. 2006;32(3):161-6. 
17. Adachi W, Lodolce AE. Use of failure mode and effects analysis in improving the safety of i.v. drug administration. Am J HealthSyst Pharm. 2005;62(9):917-20.

18. Apkon M, Leonard J, Probst L, DeLizio L, Vitale R. Design of a safer approach to intravenous drug infusions: failure mode effects analysis. Qual Saf Health Care. 2004;13(4):265-71.

19. Wetterneck TB, Skibinski KA, Roberts TL, Kleppin SM, Schroeder ME, Enloe $M$, et al. Using failure mode and effects analysis to plan implementation of smart i.v. pump technology. Am J Health-Syst Pharm. 2006;63(16):1528-38.
20. Fatehi Peikani A. A study of causes and rate of deduction imposed with social security insurance on the submitted bills of Sina Nad Firouzabadi hospitals in 1999: Iran University of Medical Sciences. [Persian]; 2000

21. Tehran University of Medical Sciences. The cost analysis of AmirAlam hospital. Imam Hossein, Tehran: 2001.

Table 1: Worksheet of analysing the most important failure causes in the Hospitalisation Unit before and after the intervention

\begin{tabular}{|c|c|c|c|c|c|c|c|c|c|c|}
\hline FAILURE MODE & FAILURE CAUSES & FAILURE EFFECTS & 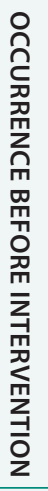 & 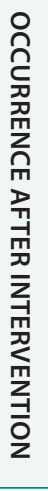 & 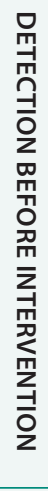 & 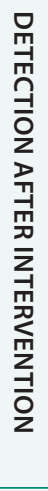 & 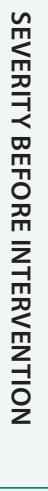 & 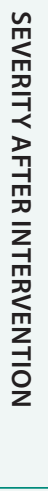 & 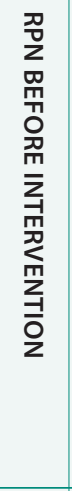 & 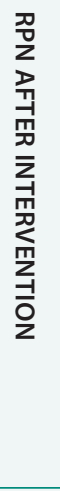 \\
\hline $\begin{array}{l}\text { Not sealing/signing the } \\
\text { procedure sheet by the } \\
\text { physician }\end{array}$ & $\begin{array}{l}\text { Disregarding by the } \\
\text { staff Physician not } \\
\text { gaining profit } \\
\text { Being very busy } \\
\text { Residents and new } \\
\text { physicians not familiar } \\
\text { Staff not motivated } \\
\text { Increasing deductions }\end{array}$ & & 8 & 8 & 5 & 4 & 8 & 8 & 320 & 256 \\
\hline $\begin{array}{l}\text { Altered procedure } \\
\text { sheet }\end{array}$ & $\begin{array}{l}\text { Staff not informed of } \\
\text { alteration consequences }\end{array}$ & $\begin{array}{l}\text { Decreasing the hospital } \\
\text { incomes }\end{array}$ & 7 & 6 & 5 & 4 & 7 & 7 & 245 & 168 \\
\hline $\begin{array}{l}\text { Incomplete filling in the } \\
\text { visit sheet }\end{array}$ & $\begin{array}{l}\text { Disregarding by medical } \\
\text { staff }\end{array}$ & & 6 & 6 & 6 & 5 & 7 & 7 & 252 & 210 \\
\hline $\begin{array}{l}\text { Date not inserted on } \\
\text { the visit sheet }\end{array}$ & $\begin{array}{l}\text { Staff forgot to insert } \\
\text { the date }\end{array}$ & $\begin{array}{l}\text { Increasing the costs for } \\
\text { reinvestigations by the } \\
\text { staff }\end{array}$ & 6 & 5 & 6 & 5 & 7 & 7 & 252 & 175 \\
\hline $\begin{array}{l}\text { Date of releasing the } \\
\text { result not recorded on } \\
\text { the consult sheet }\end{array}$ & $\begin{array}{l}\text { Physician disregarded } \\
\text { or forgot to insert the } \\
\text { date }\end{array}$ & & 6 & 6 & 6 & 5 & 8 & 8 & 288 & 240 \\
\hline
\end{tabular}


Table 2: Worksheet of analysing the most important failure causes in the Surgery Room before and after the intervention

\begin{tabular}{|c|c|c|c|c|c|c|c|c|c|c|}
\hline FAILURE MODE & FAILURE CAUSES & FAILURE EFFECTS & 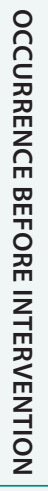 & 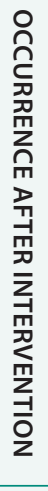 & 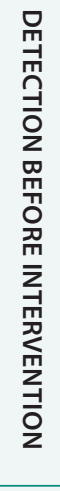 & 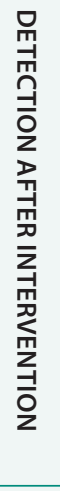 & 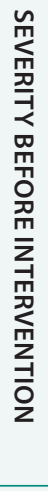 & 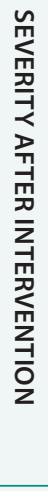 & 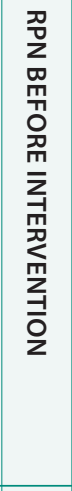 & 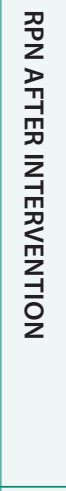 \\
\hline $\begin{array}{l}\text { Wrong code of the } \\
\text { surgery room }\end{array}$ & $\begin{array}{l}\text { Mistake by the } \\
\text { technician } \\
\text { gaining profit } \\
\text { Problem with existing } \\
\text { tariffs }\end{array}$ & Increasing deductions & 7 & 5 & 10 & 8 & 5 & 6 & 350 & 240 \\
\hline $\begin{array}{l}\text { Additional code of the } \\
\text { surgery room }\end{array}$ & $\begin{array}{l}\text { Mistake by the } \\
\text { technician } \\
\text { Problem with existing } \\
\text { tariffs }\end{array}$ & $\begin{array}{l}\text { Decreasing the hospital } \\
\text { incomes }\end{array}$ & 7 & 6 & 10 & 9 & 5 & 5 & 350 & 270 \\
\hline $\begin{array}{l}\text { Excess percentage } \\
\text { for the surgery room }\end{array}$ & $\begin{array}{l}\text { Mistake by the } \\
\text { technician } \\
\text { Problem with existing } \\
\text { tariffs }\end{array}$ & & 7 & 6 & 10 & 9 & 5 & 5 & 350 & 270 \\
\hline $\begin{array}{l}\text { Incomplete description } \\
\text { of operation for the } \\
\text { surgery commission }\end{array}$ & $\begin{array}{l}\text { Writing quality of the } \\
\text { operation description } \\
\text { disagree with } \\
\text { intruction of insuring } \\
\text { organisations }\end{array}$ & $\begin{array}{l}\text { Increasing the costs for } \\
\text { reinvestigations by the } \\
\text { staff }\end{array}$ & 6 & 5 & 9 & 9 & 6 & 6 & 324 & 270 \\
\hline $\begin{array}{l}\text { Additional code of the } \\
\text { surgery commission }\end{array}$ & $\begin{array}{l}\text { Mistake by the } \\
\text { technician } \\
\text { Problem with existing } \\
\text { tariffs }\end{array}$ & & 7 & 6 & 10 & 9 & 5 & 5 & 350 & 279 \\
\hline $\begin{array}{l}\text { Excess percentage for } \\
\text { the surgery commission }\end{array}$ & $\begin{array}{l}\text { Mistake by the } \\
\text { technician } \\
\text { Problem with existing } \\
\text { tariffs }\end{array}$ & & 7 & 6 & 10 & 9 & 5 & 5 & 350 & 270 \\
\hline
\end{tabular}


Table 3: Worksheet of analysing the most important failure causes in the Anaesthesia Unit before and after the intervention

\begin{tabular}{|c|c|c|c|c|c|c|c|c|c|c|}
\hline FAILURE MODE & FAILURE CAUSES & FAILURE EFFECTS & 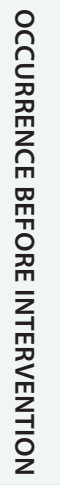 & 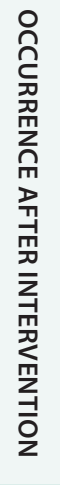 & 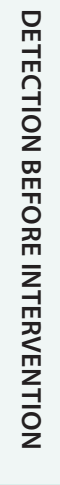 & 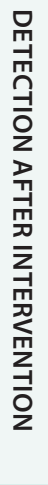 & 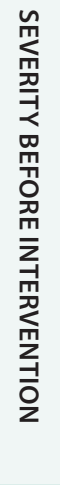 & 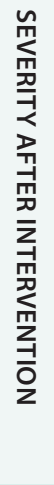 & 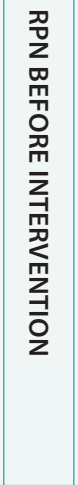 & 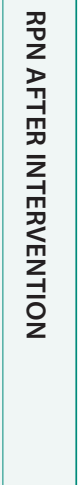 \\
\hline $\begin{array}{l}\text { Code } 51 \text { of faculty } \\
\text { ot anaestheia }\end{array}$ & $\begin{array}{l}\text { Excess charge leading } \\
\text { to coding for each } \\
\text { operation }\end{array}$ & Increasing deductions & 9 & 9 & 10 & 4 & 10 & 10 & 900 & 360 \\
\hline $\begin{array}{l}\text { Differing CVP artery } \\
\text { price of adjustment } \\
\text { faculty }\end{array}$ & $\begin{array}{l}\text { Disagreement with the } \\
\text { insurance company }\end{array}$ & $\begin{array}{l}\text { Decreasing the hospital } \\
\text { incomes }\end{array}$ & 8 & 7 & 5 & 4 & 7 & 8 & 320 & 224 \\
\hline $\begin{array}{l}\mathrm{K} 2 \text { monitoring of the } \\
\text { adjustment faculty }\end{array}$ & $\begin{array}{l}\text { Insurer not committing } \\
\text { to undertake } \\
\text { monitoring of the faculty }\end{array}$ & & 8 & 8 & 10 & 8 & 9 & 9 & 720 & 576 \\
\hline $\begin{array}{l}\text { Not having the global } \\
\text { adjustment operation } \\
\text { for the adjustment } \\
\text { faculty }\end{array}$ & $\begin{array}{l}\text { Time of the operation } \\
\text { not clear } \\
\text { Same fee paid } \\
\text { throughout the country }\end{array}$ & $\begin{array}{l}\text { Increasing the costs for } \\
\text { reinvestigations by the } \\
\text { staff }\end{array}$ & 8 & 7 & 6 & 9 & 5 & 5 & 240 & 315 \\
\hline Code 51 of anaestheia & $\begin{array}{l}\text { Excess charge leading } \\
\text { to coding for each } \\
\text { operation }\end{array}$ & & 10 & 10 & 10 & 4 & 10 & 10 & 1000 & 400 \\
\hline
\end{tabular}


Figure 1: Pareto chart of the Hospitalisation Unit before and after the intervention
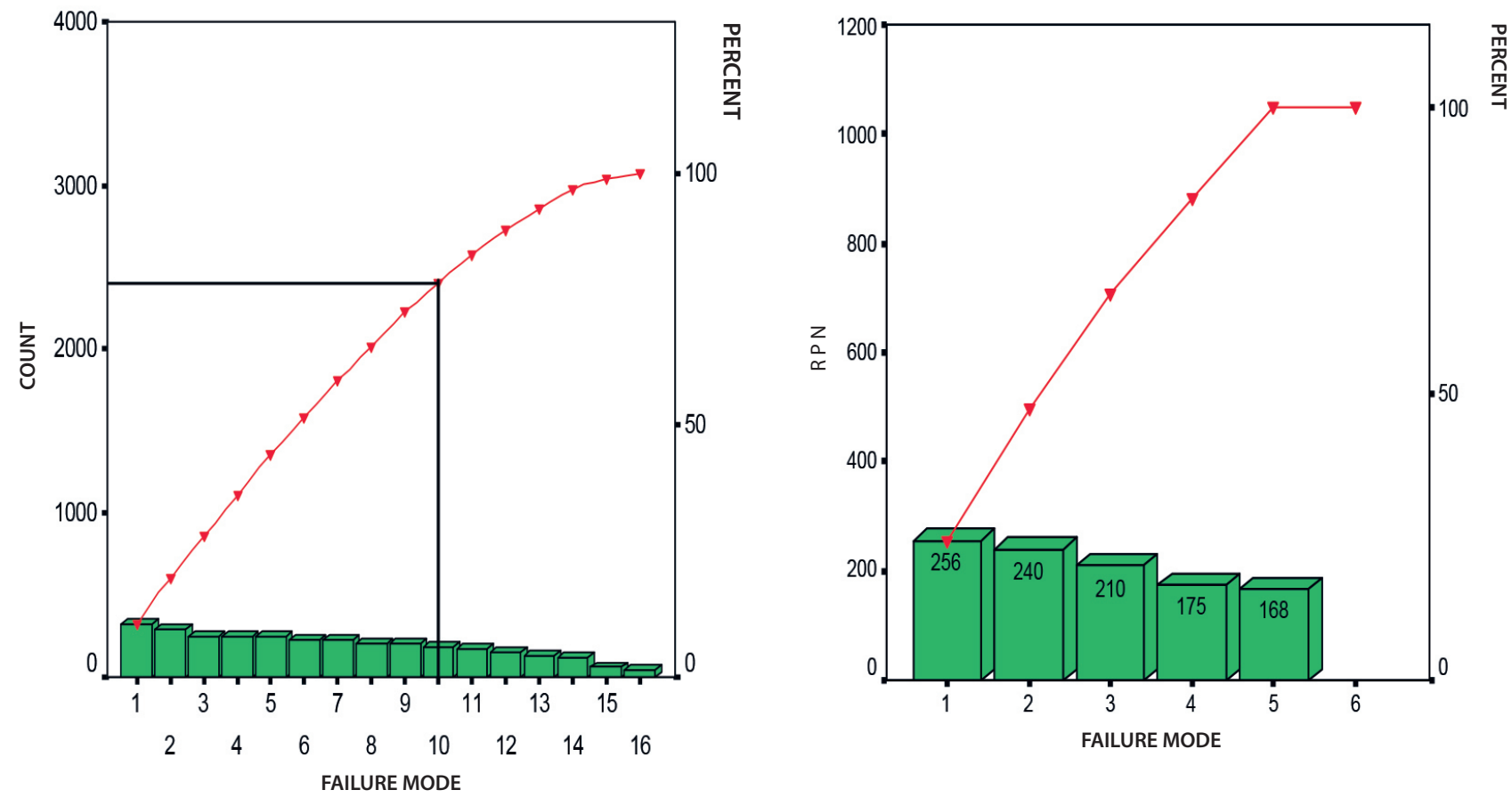

$3000 \times 80 \%=2400$

$\mathrm{RPN}>2400 \rightarrow$ Safe region

$\mathrm{RPN}<2400 \rightarrow$ Risky region

Figure 2: Pareto chart of the Surgery Room unit before and after the intervention
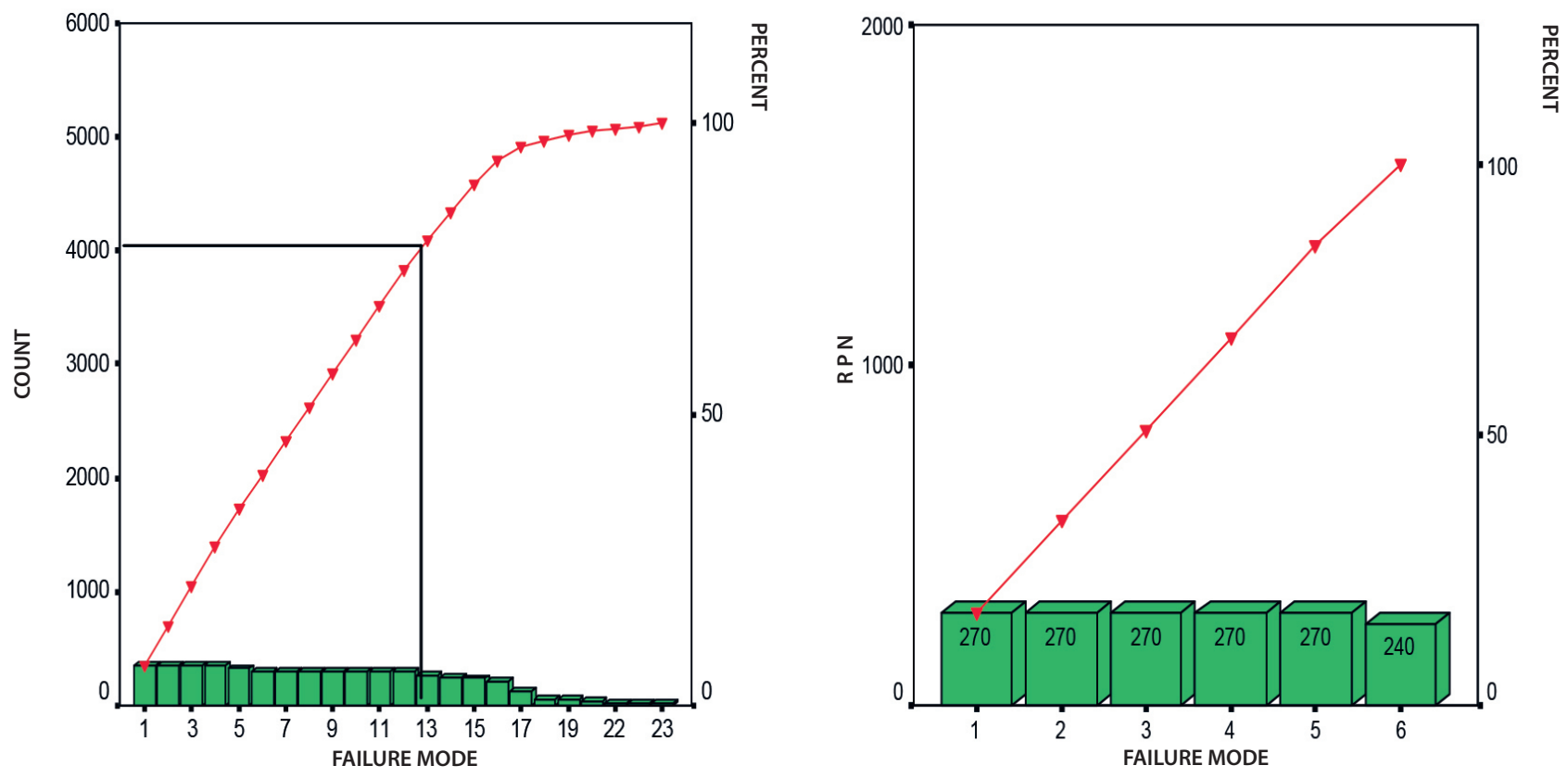

$5000 \times 80 \%=4000$

$\mathrm{RPN}>4000 \rightarrow$ Safe region

$\mathrm{RPN}<4000 \rightarrow$ Risky region 
Figure 3. Pareto chart of the Anesthesia Unit before and after the intervention failure mode
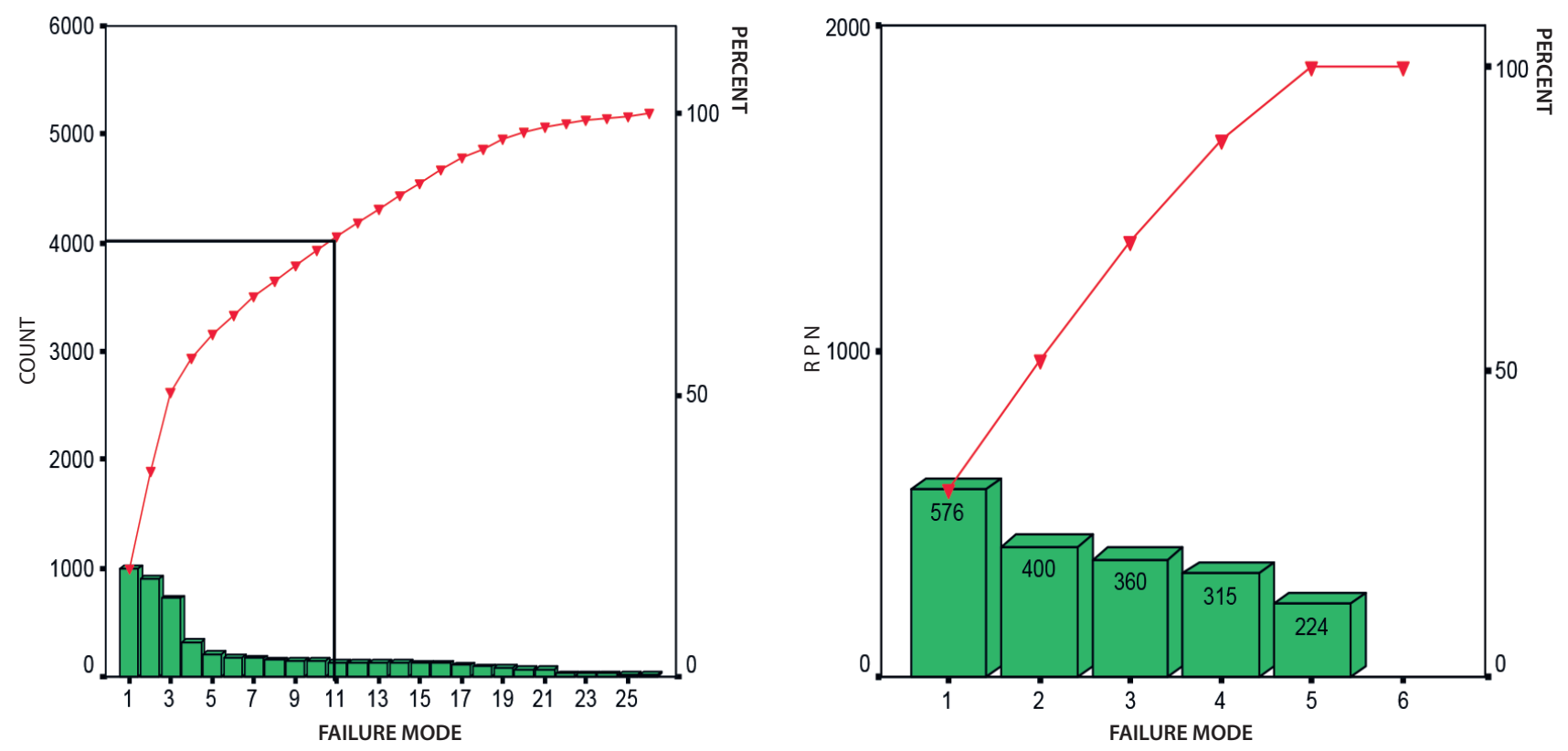

$5000 \times 80 \%=4000$

$\mathrm{RPN}>4000 \rightarrow$ Safe region

$\mathrm{RPN}<4000 \rightarrow$ Risky region 